\title{
CONFRONTACIÓN ENTRE LEGISLACIÓN Y PRÁCTICA PUBLICITARIA: SEXISMO IMPLÍCITO
}

\author{
Nazaret Martínez Heredia, Sheila Patricia Arjona Ledesma. Universidad de Granada \\ Supervisado por la profesora Gracia González Gijón. Departamento de Pedagogía. Universidad de Granada \\ Fecha de recepción: 30 de mayo de 2014. \\ Fecha de revisión: 5 de junio de 2014. \\ Fecha de aceptación: 5 de junio de 2014.
}

Resumen: La situación de la mujer ha mejorado tras la consecución de la igualdad formal de derechos; pero aun así, hoy en día perduran visiones estereotipadas de hombres y mujeres, sobre todo en los medios de comunicación. Bien es cierto que existen leyes formuladas para erradicar formas de discriminación hacia la mujer, pero aun así nuestra realidad es otra: actualmente visualizamos numerosos anuncios en los medios de comunicación que difunden estos estereotipos. Es por ello que creemos importante analizar el sexismo que se esconde en los anuncios de televisión, el cual repercutirá en la forma de construcción de las representaciones socialesde los individuos sobre cuál debe ser el papel de la mujer.Para estudiar el contenido sexista en la publicidad, analizamos diversos anuncios publicitarios, utilizando una metodología de carácter cualitativo mediante el empleode la técnica de análisis de contenido yapoyándonos en el Decálogo para una Publicidad no Sexista elaborado por el Instituto Andaluz de la Mujer. Descubrimos la enorme incongruencia existente entre la legislación analizada (Constitución de 1978, Ley Orgánica 2/2006, de 3 de mayo, de Educación y Ley 34/1988, de 11 de noviembre, General de Publicidad), y la realidad publicitaria de la que somos consumidores.

Palabras clave: Igualdad; Publicidad; Legislación; Sexismo.

\section{Introducción}

El sexismo es una forma de discriminación basada en el género, debemos tener en cuenta que mientras muchas personas utilizan este término específicamente para describir la discriminación contra la mujer, el sexismo puede ser generalizado como un subtipo de esencialismo y puede atentar contra el sexo masculino, los intersexuales y transexuales. Por lo tanto, el sexismo tiene efectos de gran alcance en la sociedad, aunque es preciso destacar que afecta en mayor medida a las mujeres, en el cual centraremos nuestro trabajo.

Para contextualizar adecuadamente el papel de la mujer en la actualidad, conviene recordar que el proyecto social tiene su origen en el pensamiento ilustrado. Existe una defensa de la igualdad hacia todos los seres humanos, sin embargo esta igualdad no será aplicada en igual medida hacia hombres y mujeres. Atendiendo a este proyecto social, el modelo político que se impondrá exigirá una mujer "doméstica", que libere al ciudadano de las preocupaciones y tareas del ámbito privado para que pueda dedicarse a lo público. Pensadores como Rousseau, filósofo de vanguardia en su época, en el Capítulo V de su obra "El Emilio" (1994), tratado sobre educación, apoya dicho modelo afirmando que, "toda educación de las mujeres debe estar referida a los hombres. Agradecerles, serles útiles, hacerse amar y honrar por ellos, criarles de pequeños y cuidarles cuando sean mayores, aconsejarles, consolarles, hacerles la vida agradable y dulce: éstos son los deberes de las mujeres de todos los tiempos y lo 
que ha de enseñárseles desde la infancia". Por lo tanto, podemos comprobar como la educación no es en sí misma un dato fijo e inmutable, sino que con el transcurso del tiempo se carga de connotaciones, en este caso, sexistas.

Actualmente, la situación de la mujer ha mejorado tras la consecución de la igualdad formal de derechos; pero aun así, hoy en día perduran visiones estereotipadas de hombres y mujeres, sobre todo en los medios de comunicación ayudando éstos a conformar una determinada visión de las pautas o roles que deben ser asumidos por ambos sexos. Bien es cierto, que existen leyes formuladas para erradicar la discriminación hacia la mujer, pero nuestra realidad es otra: actualmente visualizamos numerosos anuncios en los medios de comunicación que difunden estos estereotipos. La situación real es que el sexismo se encuentra infiltrado en la sociedad de formas tan intrínsecas que resulta complicado el erradicarlas.

La publicidad sigue siendo uno de los mecanismos más efectivos para inculcar determinados pensamientos y formas de actuación hacia otras personas. Es por ello que creemos importante el dotar de relevancia y, por tanto, analizar el sexismo (más o menos implícito) que se esconde en los anuncios de televisión, el cual repercutirá en la construcción de las representaciones sociales de género en la sociedad.

\section{Marco Teórico}

Las bases legislativas sobre las que hemos fundamentado nuestro trabajo son: la Constitución Española de 1978, la Ley Orgánica 2/2006, de 3 de mayo, de Educación y la Ley 34/1988, de 11 de noviembre, General de Publicidad.

El primer marco legal de referencia y, quizás, el más importante al que podemos recurrir, es la Constitución Española de 1978. Ésta, en su capítulo segundo, artículo número 14, reconoce la igualdad de derechos ante la ley para toda la ciudadanía española: "Los españoles son iguales ante la ley, sin que pueda prevalecer discriminación alguna por razón de nacimiento, raza, sexo, religión, opinión o cualquier otra condición o circunstancia personal o social". En su Artículo 1.1: "España se constituye en un Estado social y democrático de Derecho, que propugna como valores superiores de su ordenamiento jurídico la libertad, la justicia, la igualdad y el pluralismo político". Así como en su Artículo 9.2: "Corresponde a los poderes públicos promover las condiciones para que la libertad y la igualdad del individuo y de los grupos en que se integra sean reales y efectivas; remover los obstáculos que impidan o dificulten su plenitud y facilitar la participación de todos los ciudadanos en la vida política, económica, cultural y social". En su Artículo 10: "La dignidad de la persona, los derechos inviolables que le son inherentes, el libre desarrollo de la personalidad, el respeto a la Ley y a los derechos de los demás son fundamento del orden político y de la paz social". Finalmente en el Artículo 18. 1: "Se garantiza el derecho al honor, a la intimidad personal y familiar y a la propia imagen".

La Ley Orgánica 2/2006, de 3 de mayo, de Educaciónhace referencia al alumnado extranjero, a las víctimas del terrorismo y de actos de violencia de género, al régimen de los datos personales de los alumnos, a la incorporación de créditos para la gratuidad del segundo ciclo de educación infantil y al fomento de la igualdad de hombres y mujeres". En su artículo 1: "El desarrollo de la igualdad de derechos y oportunidades y el fomento de la igualdad efectiva entre hombres y mujeres". Así como en su Artículo 2: "La educación en el respeto de los derechos y libertades fundamentales, en la igualdad de derechos y oportunidades entre hombres y mujeres y en la igualdad de trato y no discriminación de las personas con discapacidad". En el Artículo 18: "En uno de los cursos del tercer ciclo de la etapa, a las áreas incluidas en 
el apartado anterior se añadirá la de educación para la ciudadanía y los derechos humanos, en la que se prestará especial atención a la igualdad entre hombres y mujeres". En su Artículo 23: "Valorar y respetar la diferencia de sexos y la igualdad de derechos y oportunidades entre ellos. Rechazar los estereotipos que supongan discriminación entre hombres y mujeres".En el Artículo 33: "Fomentar la igualdad efectiva de derechos y oportunidades entre hombres y mujeres, analizar y valorar críticamente las desigualdades existentes e impulsar la igualdad real y la no discriminación de las personas con discapacidad".En su Artículo 126: "Una vez constituido el Consejo Escolar del centro, este designará una persona que impulse medidas educativas que fomenten la igualdad real y efectiva entre hombres y mujeres".Dentro del Artículo 151: "Velar por el cumplimiento y aplicación de los principios y valores recogidos en esta ley, incluidos los destinados a fomentar la igualdad real entre hombres y mujeres".

Finalmente en la disposición adicional vigesimoquinta. Fomento de la igualdad efectiva entre hombres y mujeres:"Con el fin de favorecer la igualdad de derechos y oportunidades y fomentar la igualdad efectiva entre hombres y mujeres, los centros que desarrollen el principio de coeducación en todas las etapas educativas, serán objeto de atención preferente y prioritaria en la aplicación de las previsiones recogidas en la presente ley, sin perjuicio de lo dispuesto en los convenios internaciones suscritos por España".

La Ley 34/1988, de 11 de noviembre, General de Publicidad constituye el primer marco legal específico para la regulación de la actividad publicitaria en nuestro país, tras la transición democrática, aunque en algunos aspectos podemos encontrar antecedentes en la Ley 26/1984, de 19 de julio, General para la Defensa de los Consumidores y Usuarios, cuyo texto refundido ha sido aprobado por el Real Decreto Legislativo 1/2007, de 16 de noviembre, teniendo en cuenta otras leyes complementarias". "La publicidad, es una actividad que atraviesa las fronteras. La Ley no solo ha seguido las directrices comunitarias en la materia, sino que ha procurado también inspirarse en las diversas soluciones vigentes en el espacio jurídico intereuropeo".

Esta Ley, es la primera que adopta en su articulado una perspectiva de género. En los Títulos I y II se establecen las disposiciones generales y las definiciones o tipos de publicidad ilícita. En su Artículo 1. Objeto: "La publicidad se regirá por esta Ley, por la Ley de Competencia Desleal y por las normas especiales que regulen determinadas actividades publicitarias". En el Artículo 2: A los efectos de esta Ley, se entenderá por: Publicidad: "Toda forma de comunicación realizada por una persona física o jurídica, pública o privada, en el ejercicio de una actividad comercial, industrial, artesanal o profesional, con el fin de promover de forma directa o indirecta la contratación de bienes muebles". Destinatarios: "Las personas a las que se dirijan el mensaje publicitario o a las que este alcance". El Título II, Artículo 3 de la Ley General de Publicidad, modificado por la Ley Orgánica 1/2004, de 28 de diciembre, de Medidas de Protección Integral contra la Violencia de Género, señala: Artículo 3. Publicidad ilícita: Es ilícita: a. $\quad$ "La publicidad que atente contra la dignidad de la persona o vulnere los valores y derechos reconocidos en la Constitución, especialmente a los que se refieren sus artículos 14, 18 y 20, apartado 4". En el Artículo 14: "Los españoles son iguales ante la ley, sin que pueda prevalecer discriminación alguna por razón de nacimiento, raza, sexo, religión, opinión o cualquier otra condición o circunstancia personal o social". En su Artículo 18. 1: "Se garantiza el derecho al honor, a la intimidad personal y familiar y a la propia imagen". "Se entenderán incluidos en la previsión anterior los anuncios que presenten a las mujeres de forma vejatoria o discriminatoria, bien utilizando particular y directamente su cuerpo o partes del mismo como mero objeto desvinculado del producto que se pretende promocionar, bien su imagen asociada a 
comportamientos estereotipados que vulneren los fundamentos de nuestro ordenamiento coadyuvando a generar la violencia a que se refiere la Ley Orgánica 1/2004, de 28 de diciembre, de Medidas de Protección Integral contra la Violencia de Género".

\section{Método}

Este trabajo, enmarcado dentro de la investigación cualitativa, tiene como finalidad identificar los elementos sexistas del mensaje publicitario en base al Decálogo para una Publicidad no sexista del Instituto Andaluz de la Mujer y comprobar, si se adecuan a las normas de la legislatura vigente, en concreto a la Constitución Española de 1978, a la Ley Orgánica 2/2006, de 3 de mayo, de Educación y, a la Ley 34/1988, de 11 de noviembre, General de Publicidad.

\section{Muestra}

Para la selección de la muestra hemos empleado un muestreo intencional que consiste en seleccionar casos que nos han aportado abudante informaciónpara llevar a cabonuestro análisis (Patton, 1990, p.169). Hemos seleccionado varios anuncios publicitarios de índole sexista, los cuales detallamos a continuación:

El anuncio de ambientadores de "Air Wick" forma parte de una campaña que elaboró la marca de ambientadores para el hogar; compuesta por spots de 20 segundos protagonizados cada uno de ellos por distintos personajes animados de género femenino (mono, pulpo, pingüino, elefante...). En todos los anuncios de dicha campaña se repiten la misma serie de elementos: el primero de ellos sería como un animal animado protagonista de género femenino que habla de sí misma mientras realiza las tareas del hogar. Seguidamente otros animales animados representan a sus hijos, los cuales ensucian el hogar. En algunos spots aparecen sus maridos, mientras realizan actividades lúdicas o están descansando. Por último el slogan del producto acompañado por la voz en off "Air Wick, me siento bien en casa".

A parte de esta serie de elementos, todos los spots presentan el mismo diseño: el contexto es un agradable hogar donde la madre se visualiza cuidando del entorno familiar, otorgando quizá una excesiva importancia al aspecto de la limpieza y el orden hogareño y la voz en off del personaje femenino protagonista narra cómo se siente en su hogar.

El anuncio de la fragancia Invictus de Paco Rabanne forma parte de una campaña protagonizada por la marca de perfumes; en él aparece la figura de un hombre caminando por un inmenso estadio aclamado por todo el mundo. A las puertas del estadio, se vislumbra cómo dos mujeres semidesnudas con presencia de diosas dan la bienvenida al hombre, el cual es perseguido por una cantidad ingente de fotógrafos. A lo largo de todo el recorrido por el estadio, el hombre es en todo momento aclamado y visualizado como un ganador, un héroe, incluso podríamos hablar de una especie de "semidios". En cierto momento de su recorrido por el estadio aparecen de la nada un grupo de jugadores rivales de los cuales el protagonista se deshace destruyéndolos con un solo movimiento de mano, demostrando así su superioridad y fuerza. En este preciso instante, podemos ver a través de sus expresiones faciales y de su actitud corporal como tanto su ego como su autoestima se engrandecen.

En el cambio de secuencia aparece la figura de una diosa semidesnuda en un plano mayor señalando al protagonista reforzando de este modo la visión que se tiene del hombre como ser superior, capaz de todo, fuerte... En ese plano el hombre aparece 
con un trofeo al alza y se visualiza como fondo la imagen de la diosa semidesnuda. Por un instante, parece que el anuncio ha finalizado, pero no es así; tras una secuencia en la que se muestra la marca del perfume, aparece una segunda escena en la que el hombre entra en el vestuario, todavía con el trofeo en alza, en el que le están esperando cinco mujeres semidesnudas las cuales, al finalizar el anuncio, se deja entrever que se quedan desnudas; en ese momento, el hombre mira a cámara con gesto complaciente y pícaro.

Otro de los anuncios seleccionados es el de Zalando, una tienda de moda online especializada en la venta de zapatos y ropa para mujer, hombre, niños y niñas. En el spot aparece un hombre escondido en un vestidor femenino repleto de ropa, zapatos, bolsos y demás complementos que se está grabando a sí mismo con la finalidad de publicar un mensaje dirigido a todo el género masculino. Mientras emite el discurso, se observa claramente una actitud de terror debido a que su mujer ha "descubierto" Zalando; se interpreta que la finalidad de este vídeo es hacer llegar a los demás hombres un mensaje de advertencia para que sus mujeres, hermanas, madres (siempre haciendo alusión al género femenino) no descubran esta tienda de ropa online.

A medida que va describiendo lo que la mujer puede adquirir en Zalando, muestra dichas prendas las cuales están en el vestidor; finalmente se enfoca un plano de todo el vestidor repleto. Seguidamente llaman al timbre, y aparece un repartidor cargado de cajas de la marca; la mujer es la que se encarga de abrir la puerta y al toparse con su pedido emite un sonoro grito de alegría, al cual tanto su marido como el repartidor responden con un grito de terror.

En el anuncio de la marca de yogures Vitalinea SatisfAcción aparece una mujer joven, guapa y delgada que sale de casa y anda sonriente por la calle; de repente se topa con una pastelería: decide pasar de espaldas pegada al escaparate para no ver los dulces expuestos. Es entonces cuando una voz en off (femenina también) pregunta: "¿ya no sabes cómo evitar las tentaciones?”.

En otro plano, cuando la mujer está en casa y su marido está tranquilamente sentado leyendo el periódico junto a un enorme plato de dulces de grandes dimensiones; el marido se lleva a la boca una magdalena y la voz en off vuelve a formular otra pregunta: “iintentas controlarte entre horas?” La chica entonces, se tapa los ojos y sale corriendo hacia la cocina para abrir el frigorífico y coger el producto, en este instante la voz en off dice: "ayuda a recuperar el control de lo que comes con SatisfAcción, el único 0\% con ingredientes activos que te ayudan a reducir el apetito". La chica afirma lo que dice la voz en off: "es verdad, lo tomas y lo notas, esto es control"; mientras se está tomando una cucharada del producto en este plano vuelve a aparecer el enorme plato de dulces, el cual esta vez es completamente ignorado por ella.

Por último hemos seleccionado el anuncio homenaje a los 300 años de la RAE. En él vemos como un niño intenta abrir un tarro de mermelada sin éxito, ya que se le desliza y cae al suelo, manchándolo todo. En ese momento, entra a la cocina su madre hecha una fiera y dice: "pero niño no vas y tiras la frombuesa estropiciándolo todo, ende que venga tu padre lo quiero ver todo esto floresciente". En ese momento una voz en off masculina dice: "tranquila, con RAE este desastre tiene solución. El efecto RAE elimina todas la impurezas, devolviéndole al lenguaje su brillo original". Mientras escuchamos esta sentencia aparece en un primer plano el diccionario de la RAE junto a un montón de ropa perfectamente doblada, después contemplamos a la mujer abriendo el diccionario de la RAE como si éste fuera un instrumento mágico. 
Tras la utilización del diccionario de la RAE por parte de la mujer, vuelve a ocurrir la secuencia en la que el niño tira el tarro de mermelada, en esta ocasión, su madre le vuelve a transmitir el mismo mensaje estructurado en esta ocasión de manera correcta: "hijo mío, te encomiendo la tarea de dejar el suelo reluciente antes de que llegue tu padre". En la siguiente secuencia aparece la mujer portando el diccionario de la RAE mientras la voz en off narra: "demostrado: RAE limpia, fija y da esplendor".

Finalmente se muestra un mensaje de la Academia de la Publicidad que dice: "desde la Academia de la Publicidad queremos rendir homenaje a La Real Academia Española en su III centenario como mejor sabemos. Con un anuncio".

\section{Técnica de recogida de datos}

Para la recogida de datos se empleó el análisis de contenido que, según Bardin (1986), es un conjunto de técnicas cuya pretensión y objetivo es analizar las comunicaciones para lo cual utiliza procedimientos sistemáticos y objetivos de descripción del contenido de los mensajes, que nos llevó a conocer y describir, de forma empirica,los mensajes sexistas implicitos en la publicidad actual.

Para analizar estos mensajes hemos empleado el Decálogo para una Publicidad no Sexista elaborado por el Instituto Andaluz de la Mujer, que describimos a continuación (ver tabla 1):

Tabla 1. Decálogo para una Publicidad no Sexista elaborado por el Instituto Andaluz de la Mujer (2013).

1. Promover modelos que consoliden pautas Anuncios que siguen perpetuando los roles tradicionalmente asignados a cada tradicionalmente fijadas para mujeres y hombres: género, manteniendo el tradicional reparto de espacios profesionales, privados frente a públicos o de prestigio, ajenos a los cambios sociales.

2. Fijar unos estándares de belleza considerados como Anuncios que limitan los objetivos vitales de las mujeres a la adecuación a unos sinónimo de éxito: determinados patrones estéticos, llegando en ocasiones a causar presión sobre la salud física y psíquica de las adolescentes.

3. Presentar el cuerpo como un espacio de Anuncios que presentan los cuerpos de las mujeres y sus cambios debidos a la imperfecciones que hay que corregir:

4. Situar a los personajes femeninos en una posición de inferioridad y dependencia: edad como "problemas" que es preciso ocultar y/o corregir.

Anuncios que presentan a las mujeres como personas dependientes, en cualquier aspecto incluido el económico, anulando su libertad y su capacidad de respuesta y de elección.

5. Negar los deseos y voluntades de las mujeres y Anuncios que muestran a las mujeres realizados como personasen la medida en mostrar como "natural" su adecuación a los deseos y la que responden a lo que los demás les piden(hijos e hijas, el marido, el padre, voluntades de los demás: la madre...) sin respetar sus objetivos vitales y profesionales.

6. Representar el cuerpo femenino como objeto, esto es como valor añadido a los atributos de un determinado producto, como su envoltorio en definitiva:

7. Mostrar a las mujeres como incapaces de controlar sus emociones y sus reacciones, "justificando" así las prácticas violentas que se ejercen sobre ellas:

8. Atentar contra la dignidad de las personas o vulnerar los valores y derechos reconocidos en la Constitución:

9. Reflejar de forma errónea la situación real de las mujeres con discapacidad contribuyendo a la no sensibilización necesaria para un tratamiento óptimo de los temas que les afectan

10. Utilizar un lenguaje que excluye a mujeres, que dificulta su identificación o que las asocie a valoraciones peyorativas:
Anuncios que recurren al cuerpo de la mujer o al fetichismo de determinadas partes del mismo (labios, piernas, pies...) o prendas de vestir, como reclamo para atraer la mirada y la atención de la potencial clientela.

Anuncios que muestran a las mujeres movidas por caprichos, faltas de juicio en sus reacciones y comportamientos.

Anuncios que presentan a las mujeres de forma vejatoria, bien utilizando particular y directamente su cuerpo o partes del mismo como mero objeto desvinculado del producto que se pretende promocionar, o mostrando comportamientos y conductas que puedan incidirá atacar la integridad física o moral de las mujeres.

Anuncios que no colaboran a la normalización de la imagen de las mujeres con discapacidad, a través de la publicidad convencional.

Anuncios que en su mensaje usan un lenguaje discriminatorio y parcial, imponiendo barreras arbitrarias e injustas en el desarrollo profesional y colectivo de las personas

\section{Procedimiento}

Una vez seleccionada la temática en torno a la cual versaría nuestro trabajo, seleccionamos los artículos de la legislación vigente que regulan la práctica publicitaria y velan por la igualdad de hombres y mujeres. 
Posteriormente recopilamos información de distintas fuentes (anuncios publicitarios, bibliografía, páginas web) seleccionando el material que mejor se ajustaba a nuestro tema de investigación.

El siguiente paso fue plantearnos el interrogante: ¿cuándo un anuncio es sexista? Para dar respuesta a esta cuestión nos basamos en el Decálogo para una Publicidad no Sexista elaborado por el Instituto Andaluz de la Mujer. Apoyándonos en él realizamos un análisis de diversos anuncios sexistas, señalando los puntos que incumplían. Finalmente realizamos una discusión sobre el sexismo implícito hallado teniendo en cuenta la desvinculación entre legislación y práctica publicitaria.

\section{Análisis y discusión de los resultados}

Desde nuestro análisis y tomando como referencia el Decálogo para una Publicidad no Sexista elaborado por el Instituto Andaluz de la Mujer, el anuncio de ambientadores de "Air Wick" infringe los siguientes puntos:

1. Promover modelos que consoliden pautas tradicionalmente fijadas para mujeres y hombres: este spot continúa perpetuando el arcaico rol asignado al género femenino ubicado en el ámbito hogareño, es decir, alude al tradicional reparto de espacios profesionales en el que ubica a la mujer a cargo de las tareas hogareñas y cuidado de hijos y marido, privando con ello a ésta de un espacio público y manteniéndola ajena de los aspectos sociales.

4. Situar a los personajes femeninos en una posición de inferioridad y dependencia: siguiendo esta línea podemos ver como se anula la liberta del género femenino ya que debe estar cuidando a sus hijos y haciendo las tareas de la casa asumiendo en primera persona que el tener más manos supondría un alivio pero a la vez mucho más trabajo en el hogar.

5. Negar los deseos y voluntades de las mujeres y mostrar como "natural" su adecuación a los deseos y voluntades de los demás:por otro lado vemos una imagen de la mujer que solo se centra en atender a los demás (hijo/hija, ropa para el marido...) sin tener en cuenta para nada sus objetivos vitales o profesionales, ya que vemos que su profesión únicamente se centra en ser ama de casa.

Podemos destacar de esta campaña que la mujer (obviando el hecho de que en estos spots han utilizado como protagonistas personajes animados) no tiene tiempo libre entre el cuidado de los niños, su marido y las tareas domésticas para otras actividades, y que por lo tanto, debe utilizar "Air Wick" para mantener hogar con un olor fresco y limpio de forma automática. Debido a estos aspectos, se produce una feminización de los personajes, ofreciendo a la vez una perspectiva de uso mediante el lema "me siento bien en casa".

En resumen, podemos ver que dichos puntos del decálogo nos muestran a una mujer que está alejada de todo espacio profesional, de ocio, etc, asignándole roles relacionados con la limpieza, el cuidado a los demás... Podemos decir, por tanto que las protagonistas de esta marca son en todos los casos madres que atienden las tareas del hogar, así como el cuidado de los hijos ya que sus maridos trabajan fuera de casa o están realizando tareas como componer partituras musicales y tocar el piano como aparece en este caso concreto.

Por otro lado, vemos como la familia que se muestra en el anuncio hace referencia a una familia tradicional, con una estructura patriarcal en la que el hombre es quien 
posee la máxima autoridad sobre la mujer y sobre sus hijos, reforzando así la imagen de la maternidad como objetivo primordial de las mujeres, siendo, en justa correspondencia, la no maternidad vista como algo negativo que no deja que la mujer se realice al completo como persona. Podemos observar una estructura de género y de familia ideal en base a una ideología dominante.

Finalmente nos gustaría destacar el hecho de que sus protagonistas sean inofensivos dibujos animados, éste es un aspecto muy relevante a tener en cuenta, ya que parece que los dibujos son algo muy inocentes pero el mensaje que se esconde es tremendamente sexista: "mamas-animalito" que se encuentran encantadas con su forma de vida y que su mundo únicamente se centre en su hogar y su familia diciendo "me siento bien en casa". Al ser dibujos animados constituyen un elemento muy atractivo para nuestros menores, los cuales sin darse cuenta y sin ser conscientes normalizan y asumen estos roles.

El siguiente análisis se centra en el anuncio publicitario de la fragancia Invictus de Paco Rabanne. Éste infringe los siguientes puntos:

1. Promover modelos que consoliden pautas tradicionalmente fijadas para mujeres y hombres: al rol desempeñado por el hombre en este anuncio se le atribuyen características como la fuerza, el heroísmo, la superioridad...; mientras que la imagen de la mujer se muestra como objeto de deseo por parte del hombre, y las características que se le atribuyen son sumisión y belleza.

2. Fijar unos estándares de belleza considerados como sinónimo de éxito: las mujeres que aparecen en el anuncio, consideradas como trofeo/ objeto de belleza presentan una estética caracterizada por una figura esbelta, de extrema delgadez y, en definitiva, cánones no representativos de la sociedad.

4. Situar a los personajes femeninos en una posición de inferioridad y dependencia: esto se muestra cuando las mujeres se encuentran en el vestuario esperando al hombre, éstas constituyen el trofeo del protagonista.

5. Negar los deseos y voluntades de las mujeres y mostrar como "natural" su adecuación a los deseos y voluntades de los demás: anulando de este modo su capacidad de respuesta o elección, caracterizándolas de sumisas al entenderse que las cinco mujeres van a mantener relaciones sexuales con él.

6. Representar el cuerpo femenino como objeto, esto es, como valor añadido a los atributos de un determinado producto, como su envoltorio en definitiva: en este anuncio se alude en repetidas ocasiones al cuerpo de la mujer como trofeo. Podemos decir que las mujeres del anuncio, las cuales están semidesnudas e incluso en ciertos momentos se dejan entender que se desprenden de su indumentaria; se muestran como reclamo para atraer la atención de consumidores potenciales.

8. Atentar contra la dignidad de las personas o vulnerar los valores y derechos reconocidos en la Constitución: las mujeres son representadas de forma vejatoria puesto que el objetivo del anuncio es el promocionar una fragancia, pero independientemente de esto, la figura de la mujer semidesnuda aparece en numerosas ocasiones. En otras palabras, el cuerpo de la mujer es utilizado como un mero objeto de reclamo el cual se encuentra desvinculado completamente con la finalidad del anuncio, que es promocionar una fragancia. 
Como elementos característicos de este anuncio, señalamos el contexto en el que se ubica, es decir, un grandioso estadio repleto de gente que aclama al hombre, otorgándole así protagonismo y poder. Si lo comparamos con los contextos en los que se ubican a las mujeres, comprobamos que la distancia entre unos y otros resulta extrema ya que la mujer aparece en la mayoría de las ocasiones en el ámbito del hogar. Por otro lado, mientras que la figura del hombre es contemplada como un ser superior, fuerte, buen amante, invencible...; las mujeres en cambio son concebidas como trofeos, objeto de deseo, sumisas...cualidades en las que siempre prima la belleza.

Consideramos destacable el hecho de que el propio frasco de la fragancia es un trofeo, lo cual adquiere una simbolización subliminal que hace referencia a la mujer como objeto de deseo.

En resumen, podemos ver que dichos puntos del decálogo nos muestran las enormes diferencias existentes en torno a las características atribuidas a hombres y mujeres, en las que se muestra la primacía del sexo masculino. Por otro lado, destacamos la explícita relación entre mujer-sexo, convirtiéndose esta en una gratificación sexual (trofeo) para el protagonista del anuncio, debido al hecho de que en nuestra sociedad existe la equívoca ideología de que el sexo forma parte preferentemente de la vida del hombre que de la mujer.

Como elemento relevante a destacar surge la vinculación inherente entre mujer como objeto de deseo y la importancia de la estética que ello conlleva; es decir, para que ésta sea considerada como tal, ha de adecuarse a unos cánones de belleza, moda, medidas, estética... prefijados por la sociedad que no son reales. La sociedad sigue perpetuando este tipo de ideologías, que pueden llegar a repercutir en nosotros de una manera perjudicial, al intentar alcanzar este difícil canon de belleza.

El anuncio publicitario de la tienda de moda online Zalando infringe los siguientes puntos:

4. Situar a los personajes femeninos en una posición de inferioridad y dependencia: la mujer posee una dependencia económica con respecto a su marido, que es quien administra la economía, de ahí su queja: "esa tienda online de moda me ha destrozado la vida". De ello se desprende el hecho de que a la mujer se le adjudica el rol de compradora compulsiva, desquiciada, movida por acciones impulsivas que la abocan al consumo desenfrenado e innecesario sin tener en cuenta el estado de la economía familiar.

7. Mostrar a las mujeres como incapaces de controlar sus emociones y sus reacciones: se visualiza a la mujer como una persona que actúa sin pensar, movida única y exclusivamente por el impulso del consumismo en exceso ya que se muestra que su vestidor está repleto y aun así "necesita" seguir adquiriendo nuevos caprichos.

A partir de estos puntos del decálogo, observamos nuevamente el distinto trato que se atribuye a hombres y mujeres en la práctica publicitaria. De esta campaña analizamos principalmente dos aspectos:

El primero de ellos tiene que ver con el sector de la población al que va dirigido este anuncio. Tras la visualización del spot, creímos que el consumidor potencial de esta marca era exclusivamente femenino, ya que así es cómo queda reflejado en el anuncio. Indagando un poco más, visitamos la página web de Zalando, la cual se define como "una tienda de moda online especializada en la venta de zapatos y ropa 
para mujer, hombre y niños/as". El segundo está relacionado con un intento de mejora del anuncio y decimos un intento de mejora porque opinamos que no es así. El spot fue modificado de la siguiente manera; ahora el marido en su mensaje de alerta dice: "jamás dejes que nadie descubra Zalando.es. Esa tienda online de moda me ha destrozado la vida. Zapatos, ropa, bolsos de todas las marcas y lo peor de todo... los envíos y las devoluciones son gratis".

En el segundo spot que lanzó la marca, el hombre que está transmitiendo el mensaje modifica el sujeto; en lugar de "tu mujer, novia o hermana" dice "nadie". Por lo tanto creemos que es un intento fallido ya que sigue mostrando a la mujer como compradora compulsiva puesto que las escenas no han sido modificadas, solamente lo ha sido una pequeña parte del mensaje del marido.

El anuncio publicitario de la marca de yogures VitalineaSatisfAcción infringe los siguientes puntos:

1. Promover modelos que consoliden pautas tradicionalmente fijadas para mujeres y hombres: quizá en este anuncio pasa un poco desapercibido, pero comprobamos que nuevamente, el contexto en el que se ubica a la mujer vuelve a ser la cocina y el hogar; mientras que el hombre se encuentra de forma relajada leyendo el periódico en el salón.

2. Fijar unos estándares de belleza considerados como sinónimo de éxito: la mujer ha de marcarse unas pautas alimenticias adecuándose a unos determinados patrones estéticos caracterizados por la delgadez, así lo muestran las afirmaciones de la voz en off: "¿ya no sabes cómo evitar las tentaciones?”, “iintentas controlarte entre horas?”, "ayuda a recuperar el control de lo que comes con SatisfAcción, el único $0 \%$ con ingredientes activos que te ayudan a reducir el apetito" y "SatifAcción de Vitalinea, te ayuda a controlar tu apetito y tu peso".

3. Presentar el cuerpo como un espacio de imperfecciones que hay que corregir: el género femenino ha de mantener su figura siempre esbelta, delgada; o de lo contrario ello sería un problema.

7. Mostrar a las mujeres como incapaces de controlar sus emociones y sus reacciones: muestra a la mujer con falta de juicio en sus desmesuradas reacciones y comportamientos al ver los dulces.

Como elementos característicos de este anuncio destacamos nuevamente la enorme diferencia de trato existente en el rol adquirido entre hombres y mujeres en los anuncios televisivos; una vez más, la mujer se ubica en el contexto de la cocina, mientras que el hombre se encuentra en otras áreas del hogar, en este caso, el salón.

Otro elemento destacable es que al comienzo del anuncio, pasan dos mujeres maduras por delante de la pastelería y no ocurre ningún tipo de reacción por su parte; pero al pasar la chica joven, ésta actúa de forma desmesurada... Debido a este hecho pretendemos mostrar que los anuncios sexistas de esta índole, siempre pretenden hacer pensar que las chicas jóvenes han de "tener la obligación" y una imposición subliminal de poseer un cuerpo perfecto.

Comprobamos que todas las reacciones de los hombres (el pastelero, los dos hombres que caminan por la calle y el propio marido), son de un gran asombro al ver el comportamiento desmesuradoque se adjudica a la mujer. 
Destacamos que el pastelero es un hombre cuya apariencia física denota cierta dejadez. Asimismo el marido está plácidamente disfrutando de los dulces mientras que la mujer no puede ni si quiera contemplarlos debido a que ha de controlar sus impulsos para mantener su peso ideal.

Este tipo de anuncios, en los que las mujeres han de adecuar su alimentación y por tanto, su peso, a unos estrictos cánones establecidos por la sociedad puede llegar a causar presión y situaciones extremas con graves problemas psicológicos.

Para terminar hemos el anuncio publicitario de homenaje a los 300 años de la RAE, infringiendo éste los siguientes puntos del decálogo:

1. Promover modelos que consoliden pautas tradicionalmente fijadas para mujeres y hombres: nuevamente, es la mujer la que aparece ubicada en la cocina mientras que el hombre está trabajando fuera del hogar. Asimismo, se desprende cómo le son asignadas a la mujer las tareas propias del hogar: lavar y doblar la ropa, cuidar al hijo y mantener la casa en orden.

4. Situar a los personajes femeninos en una posición de inferioridad y dependencia: la mujer es dependiente de su marido, el cual es la figura que sustenta la economía familiar y por tanto, el que tiene el poder en el hogar.

7. Mostrar a las mujeres como incapaces de controlar sus emociones y sus reacciones: la madre es mostrada como una persona histérica incapaz de controlar sus reacciones ante un hecho insignificante.

8. Atentar contra la dignidad de las personas o vulnerar los valores y derechos reconocidos en la Constitución: la mujer es representada de forma vejatoria puesto que se promociona un producto en el cual ella es tildada de inculta, atacando de este modo a su integridad moral.

Estimamos oportuno destacar de esta campaña publicitaria numerosos aspectos:

Consideramos que éste es un anuncio con una potente carga sexista, pero ésta se muestra de manera implícita, debido a que se encubre mediante la risa y la diversión.

Es un niño el que intenta abrir el tarro de mermelada. Parece algo normal, pero analizado desde nuestra visión, volvemos a percibir que la característica de la fuerza vuelve a ser atribuida al género masculino.

La madre entra en la cocina y su reacción ante un hecho tan insignificante como es el de derramar un tarro, es sumamente desmesurado.

Es la voz en off de un hombre la que sosiega a la mujer diciendo: "tranquila, con RAE este desastre tiene solución. El efecto RAE elimina todas la impurezas, devolviéndole al lenguaje su brillo original".

El vocabulario utilizado por la mujer a la hora de reprender a su hijo denota que ella es una persona inculta.

Nuevamente el contexto en el que transcurre el anuncio es en la cocina; asimismo, en cierto momento del spot se extrae que el marido está trabajando fuera de casa. Por tanto, nuevamente vuelven a repetirse roles asignados a cada uno de los géneros. 
En ciertos momentos se nos "olvida" que el producto anunciado es el diccionario de la RAE, puesto que la Academia de la Publicidad elaboró el anuncio de forma en la que parece que lo que se nos está vendiendo es un producto de limpieza en los que la mujer siempre aparece como protagonista. Destacamos de ello la creencia de que, como a las mujeres le es atribuido el desempeñar a la perfección las tareas del hogar, creemos que el diccionario de la RAE aparece al lado de un montón de ropa perfectamente doblada ya que si la mujer asume el aprendizaje y la utilización del lenguaje de la misma manera en que desempeña las tareas del hogar, el resultado (tal y como se muestra en la repetición de la secuencia) será perfecto en cuanto a estructura, vocabulario y uso del lenguaje.

De nuevo, comprobamos la dependencia de la mujer con respecto al hombre al escuchar frases tales como: "pero niño no vas y tiras la frombuesaestropiciandolo todo, ende que venga tu padre lo quiero ver todo esto floresciente" o "hijo mío, te encomiendo la tarea de dejar el suelo reluciente antes de que llegue tu padre". Por tanto, vuelve a mostrarse la ideología predominante de familia ideal (padre, madre e hijo).

El hecho de que este anuncio haya sido elaborado por la Academia de la Publicidad: "desde la Academia de la Publicidad queremos rendir homenaje a La Real Academia Española en su III centenario como mejor sabemos. Con un anuncio", dista mucho de ser un homenaje hacia la RAE y lo que la Academia de la Publicidad ha conseguido con él, ha sido desprestigiar e infravalorar la figura de la mujer a través de la risa fácil.

\section{Conclusiones}

Como principal conclusión de nuestro trabajo podemos afirmar que existe una enorme incongruencia entre la legislación vigente que regula la práctica publicitaria y vela por la igualdad de hombres y mujeres y la realidad publicitaria de la que somos consumidores.

Hemos constatado, que muchos de los puntos del Decálogo para una Publicidad no Sexista del Instituto Andaluz de la Mujer, están basados en numerosos artículos promulgados por la legislación en las que hemos fundamentado nuestro trabajo y que en cada uno de los anuncios analizados, se llegan a incumplir varios puntos de dicho decálogo. Por tanto, confirmamos que legislación y práctica están totalmente desvinculadas. Esto nos lleva a formularnos la siguiente pregunta: ¿cuáles son los motivos por lo que se siguen perpetuando actitudes sexistas en la actualidad?La sociedad tiene tan intrínsecamente asumido este tipo de roles que la publicidad se aprovecha de ello para realzar sus ventas; en otras palabras, los anuncios publicitarios hacen uso, para su propio beneficio, de estrategias que resultaran beneficiosas en la venta de su producto. Algunas de éstas estrategias, extraídas del análisis de los anuncios, son: la promulgación de un ideal de familia patriarcal, el estereotipo de mujer como objeto de deseo, dependiente, ignorante, sumisa, histérica, la promulgación de unos cánones de belleza, cuidado de los hijos y realización de tareas del hogar, asignación de contextos determinados para cada sexo... Estos aspectos distan mucho de la realidad social, ya que ésta no es la que se nos muestra en los anuncios. He aquí el papel fundamental que juega la educación como factor de transformación social para evitar que sigan perpetuándose este tipo de ideologías sexistas hacia la figura de la mujer, la transmisión de una obsoleta herencia cultural, la reproducción de estereotipos ligados al género, etc.

Como profesionales de la educación ponemos de manifiesto la necesidad de educar bajo los parámetros de un pensamiento crítico ante determinadas actitudes 
promulgadas en los medios de comunicación. Remarcamos la importancia y necesidad de creación de este pensamiento crítico ya que es la herramienta necesaria para descubrir lo que la ideología dominante enmascara, que en el caso de nuestra investigación, es el sexismo implícito en los anuncios publicitarios.

Destacamos la importancia de los artículos relativos a la igualdad entre hombres y mujeres reflejados en la LOE. Volvemos a comprobar que la práctica legislativa educativa recoge de forma correcta numerosos aspectos sobre la igualdad de género, pero creemos necesaria una mayor implantación real en las instituciones educativas a través de campañas, jornadas...

Finalmente nos gustaría añadir que existe en nosotras una actitud esperanzadora porque comprobamos, que a pesar de que existen multitud de anuncios sexistas, que también existe un número cada vez mayor de personas sensibilizadas con esta causa. Un claro ejemplo de ello, es el Observatorio de la Imagen de las Mujeres, creado en 1994 por el Instituto de la Mujer del Ministerio de Trabajo y Asuntos Sociales, erigido como una herramienta ciudadana a través de la cual, particulares y colectivos pueden canalizar sus quejas en relación a la imagen de las mujeres en la publicidad, y el Observatorio Andaluz de la Publicidad no Sexista, el cual es un instrumento de análisis del discurso publicitario puesto en marcha desde 2003 por el Instituto Andaluz de la Mujer con la finalidad de cumplir con los objetivos de garantía de igualdad y respeto a la dignidad de las mujeres. Ambos elaboran un informe anual cuya finalidad es la de mostrar de forma estadística y sintetizada (indicadores, acciones y metodología) el impacto y el desarrollo que las Políticas de Género e imagen de las mujeres.

\section{Bibliografía}

Bardin, L. (1986). Análisis de contenido. Madrid: Akal.

Constitución Española 1978. [http://www.lamoncloa.gob.es]

Instituto Andaluz de la Mujer. Consejería de Igualdad, Saludo y Políticas Sociales. [http://www.juntadeandalucia.es/institutodelamujer]

Lameiras Fernández, M. (2004). El sexismo y sus dos caras: de la hostilidad a la ambivalencia. Anuario de Sexología, 8, 91-102.

Ley Orgánica 2/2006, de 3 de mayo, de Educación. [http://www.boe.es]

Ley 34/1988, de 11 de noviembre, General de Publicidad. [http://www.boe.es]

Observatorio de la Imagen de las Mujeres. [http://www.inmujer.gob.es]

Patton, MQ. (1990). Qualitative evaluation and research methods. New Park: Sage.

Santonja, P. (1994). El Eusebio de Montegón y el Emilio de Rousseau, el contexto histórico. Alicante: Instituto de Cultura "Juan Gil-Albert". 